\title{
IN VITRO STUDY OF URSOLIC ACID COMBINATION FIRST-LINE ANTITUBERCULOSIS DRUGS AGAINST DRUG-SENSITIVE AND DRUG-RESISTANT STRAINS OF MYCOBACTERIUM TUBERCULOSIS
}

\author{
DIAN AYU EKA PITALOKA*, ELIN YULINAH SUKANDAR
}

Department of Pharmacology and Clinical Pharmacy, School of Pharmacy, Institut Teknologi Bandung, Gedung Yusuf Panigoro, Jalan Ganesha, No.10, Bandung 40132, West Java, Indonesia. Email: dianayuekapitaloka@gmail.com

Received: 13 December 2016, Revised and Accepted: 29 December 2017

\section{ABSTRACT}

Objective: The resurgence of tuberculosis (TB) caused by Mycobacterium TB (MTB) is associated with the rapid spread of multidrug-resistant, therefore, the development of new antimycobacterial agents is necessary. The aim of this study was to evaluate the antimycobacterial activity of ursolic acid (UA) when it using alone and combination with TB drugs.

Methods: MTB H37Rv strain, streptomycin-rifampicin resistant strain, and isoniazid-ethambutol resistant strain were evaluated by susceptibility test using a serial number of UA (25-150 $\mu \mathrm{g} / \mathrm{mL})$. Minimum inhibitory concentration (MIC) was read as minimum concentration of drugs that completely inhibit visible growth of organism. Activities of drug combination of UA with TB drug were determined in Lowenstein-Jensen media by calculating the fractional inhibitory concentration index.

Results: The results showed that MIC of UA was $50 \mu \mathrm{g} / \mathrm{mL}$ against three different strains of MTB. The combination of UA and TB drugs displayed synergistic interaction, and no antagonism result from the combination was observed for strains of MTB.

Conclusion: These results indicate that UA may serve as a promising lead compound for future antimycobacterial drug development.

Keywords: Ursolic acid, Tuberculosis, Drug combination, Susceptibility test.

(c) 2017 The Authors. Published by Innovare Academic Sciences Pvt Ltd. This is an open access article under the CC BY license (http://creativecommons. org/licenses/by/4. 0/) DOI: http://dx.doi.org/10.22159/ajpcr.2017.v10i4.16582

\section{INTRODUCTION}

Tuberculosis (TB) is the world's second most common cause of death by infectious disease. It has been estimated that one-third of the world's population is infected with Mycobacterium TB (MTB) and 10\% of these people will become active patients during their lifetime [1]. The situation is getting worse day by day owing to the emergence of multidrug-resistant (MDR) TB strains and its association with human immunodeficiency virus or acquired immunodeficiency syndrome renders its control more difficult. In 2014, 4800,000 people developed MDR TB in the world and 1.9\% of TB cases with MDR-TB in Indonesia [2]. Thus, there is an urgent need to discover new anti-TB agents that are effective in TB treatment not only new synthetic drugs but also natural products are potential sources of new antimycobacterial products.

Ursolic acid (UA) is pentacyclic triterpenoid which considered as ubiquitous triterpenoids in the plant kingdom. It has low solubility in water and high lipophilicity [3]. This triterpene is quite interesting because it demonstrated variety biological effects such as antiinflammation, hepatoprotection, antihyperglycemia, and antitumor promotion [4]. Research conducted by López-García et al. [5] shown that UA causes a decrease in the growth and development of MTB in macrophages, stimulates the production of nitric oxide in the early phase, and stimulate to suppress transforming growth factor-alpha (TGF- $\alpha$ ) and TGF- $\beta$. In addition, dichloromethane extract Duroia macrophylla which contained UA showed a significant reduction of activity in rats induced by MTB H37Rv sensitive strain and MDR strain [6]. Meanwhile, synergistic interaction of UA when it is used combination with the first-line anti-TB drugs is still unclear.

This study investigated the in vitro antimycobacterial activity of UA against three different strains of MTB (H37Rv sensitive strain, streptomycin-rifampicin (RMP) resistant strain, and isoniazidethambutol resistant strain) when is used as individual and combination with first-line anti-TB drugs. Minimum inhibitory concentration (MICs) values and fractional inhibitory concentration (FICIs) were used in order to assess the synergistic activity of UA.

\section{METHODS}

Reagents and antibiotics

UA was purchased from Bio Basic Canada Inc. Markham Ontario, Canada. It was dissolved in dimethyl sulfoxide (DMSO) (Merck) as a solvent. The antibiotics RMP, isoniazid (INH), streptomycin (STR), and ethambutol (EMB) were purchased from Sigma-Aldrich. INH, STR, and EMB were prepared in deionized water, and RMP was prepared in dimethylformamide (Merck). DMSO was used as an appropriate solvent control with the concentration of $0.5 \% \mathrm{v} / \mathrm{v}$ [7].

\section{Microorganism}

The antimycobacterial activity was evaluated using MTB H37Rv sensitive strain, streptomycin-RMP resistant strain, and isoniazidethambutol resistant strain. All bacterial strains were provided from Balai Pengembangan Laboratorium Kesehatan Provinsi Jawa Barat. Bacterial strains were maintained by subculture on Ogawa $3 \%$ favorable to their growth for 3 weeks at $37^{\circ} \mathrm{C}$.

\section{Determination of antimycobacterial susceptibility in vitro}

The antimycobacterial activities of UA and INH, RMP, STR, and EMB against three different type of MTB were tested by susceptibility test using proportion method in Lowenstein-Jensen (LJ) media. The inoculum was adjusted to $3 \times 10^{6} \mathrm{cfu} / \mathrm{mL}$ by comparison with Mc. Farland no.1 turbidity standard and $100 \mu \mathrm{l}$ bacterial suspension containing approximately $3 \times 10^{5}$ $\mathrm{cfu} / \mathrm{mL}$ were spotted onto LJ media in Mc Cartney tubes. Cultivation was done at $37^{\circ} \mathrm{C}$ for 8 weeks, and MICs were read as minimum concentrations of drugs completely inhibiting visible growth of the organism.

\section{Activities of drug combinations}

The effects of combinations of UA and anti-TB drugs (STR, RMP, INH, or EMB) were determined as described as determination of MICs. $1 /{ }_{8}, 1 / 4$, 
and $1 / 2$ of MIC UA and anti-TB drugs were combined and tested in LJ media using susceptibility test. Interpretation data were achieved by calculating the FICIs as described by De Logu et al. [6]

FICI $=\frac{\text { MICA combination }}{\text { MICAalone }}+\frac{\text { MICBcombination }}{\text { MICBalone }}$

Interpretation data of FICI of the results as follows: FICI $\leq 0.5$, synergis; FICI 0.5-4, no interaction; FICI >4.0; antagonism.

\section{RESULTS}

Antimycobacterial susceptibility in vitro

The MICs of UA was determined according to susceptibility test using proportion method as described in methods. MIC of MTB in different strains is showed in Table 1. According to that data, it can be shown that UA can inhibit the growth of MTB in all different strains at concentration $50 \mu \mathrm{g} / \mathrm{mL}$

STR, INH, RMP, and EMB were used as drug control in determining MIC of UA and anti-TB drugs. The antimycobacterial susceptibility test results showed that $\mathrm{H} 37 \mathrm{Rv}$ strain is sensitive to all anti-TB drugs used in this study. RMP-streptomycin resistant strain was found to be resistant to both RMP and STR, and isoniazid-ethambutol resistant strain was showed to be resistant to both INH and EMB.

\section{Combination testing}

The results of the combination of UA with STR, INH, RMP, EMB, or all first-line drugs of anti-TB are listed in Table 2. The MIC for antiTB drugs used in this combination study are streptomycin $4 \mu \mathrm{g} / \mathrm{mL}$, isoniazid $0.2 \mu \mathrm{g} / \mathrm{mL}$, RMP $40 \mu \mathrm{g} / \mathrm{mL}$, and ethambutol $2 \mu \mathrm{g} / \mathrm{mL}$. The combination of UA and STR, INH, RMP, EMB, and all first-line drugs of TB showed synergistic activity with FICI values $\leq 0.5$. No interaction was found when UA in combination with STR or RMP against RMP-

Table 1: MICs of UA against drug-sensitive and drug-resistant strains of Mtb

\begin{tabular}{llll}
\hline Properties & \multicolumn{2}{l}{ Strain of Mycobacterium tuberculosis } \\
\cline { 2 - 4 } & \multicolumn{2}{l}{ MIC \pm standard deviation $(\mu \mathrm{g} / \mathrm{mL})$} \\
\cline { 2 - 3 } & H37Rv sensitive & $\begin{array}{l}\text { Streptomycin- } \\
\text { rifampicin } \\
\text { resistant }\end{array}$ & $\begin{array}{l}\text { Isoniazid- } \\
\text { ethambutol } \\
\text { resistant }\end{array}$ \\
\hline UA & $50 \pm 0$ & $50 \pm 0$ & $50 \pm 0$ \\
\hline
\end{tabular}

SD: Standard deviation; in vitro MIC values are the means \pm standard deviation, $\mathrm{n}=3$, MIC: Minimum inhibitory concentration, UA: Ursolic acid streptomycin resistant strains but the synergistic effect was showed when UA combined with INH, EMB, or all first-line drugs. No interaction result was also found when UA combined with INH and EMB against isoniazid-ethambutol resistant strains, but the synergistic interaction was also showed as the result of the combination UA with STR, RMP, and all first-line drugs. The MICs of UA against drug-sensitive strain and drug-resistant strains are significantly decreased ranging from 6.25 to $25 \mu \mathrm{g} / \mathrm{mL}$ and also the MICs of anti-TB drugs, respectively. The FICI values were showed ranging from 0.25 to 0.5 and some of the combination found to have FICI values of 1 . Noticeably, no antagonism result from the combination of UA with anti-TB drugs observed for any of the strains tested.

\section{DISCUSSION}

Until now, the treatment for this infection needs three to five different drugs simultaneously, depending on the patient category. These antiTB drugs can be given as single-drug formulations or as fixed-dose combination formulations where two or more anti-TB drugs are present in fixed proportions in the same formulation [8]. Each of the anti-TB drugs has a major role in killing of MTB. For example, INH is the most widely used first-line anti-TB drugs. This bactericidal activity has critical early in therapy which rapidly reduces the sputum viable count because it is active mainly against the organisms growing aerobically in pulmonary cavities [9]. RMP is important in killing organisms that are metabolizing slowly, killing the persisters, and sterilizing the patient's sputum [10]. EMB is the first-line drug that is used in combination with INH and RMP. EMB is a bacteriostatic that interferes the biosynthesis of cell wall arabinogalactan [11]. Streptomycin is an alternative first-line anti-TB drug recommended by WHO. This aminocyclitol glycoside has been demonstrated to take place at the ribosomal level [12].

Treatment of drug resistant in MTB has become a major problem worldwide and more serious because of the resistant fenomena. The cell wall hydrophobicity of MTB naturally prevents diffusion and binding of many drugs. Moreover, this mycobacterium has many efflux pumps which contribute to expel the drugs rapidly before they enter to the site action [13]. Based on that fenomena, development of new antimycobacterial agent becomes necessary. UA is pentacyclic triterpenes that widely found in several plants and reported to have many activities. Several studies showed that pentacyclic triterpenes to be responsible for the antimycobacterial activity.

UA ( $3 \beta$-hydroxy-urs- 12-en-28-oic acid) is an isomer from oleanolic acid (OA) (3ß-hydroxy-olea-12-en-28-oic acid) which differs in the position of a methyl residue attached to position 19 or 20 of the cyclic ring system (Fig. 1). They are pentacyclic triterpenes in the form of free acid or aglycones for triterpenoid saponin [14]. Study conducted by Wójciak-Kosior [15] reported that these compounds have similar

Table 2: Combination testing of UA and antituberculosis drugs against different strains of Mycobacterium tuberculosis

\begin{tabular}{|c|c|c|c|c|}
\hline Drug combination & Status of strains & Combination MICs \pm standard deviation $(\mu \mathrm{g} / \mathrm{mL})$ & FICIs & Conclusion \\
\hline \multirow[t]{3}{*}{ UA/STR } & $\mathrm{H} 37 \mathrm{Rv}^{\mathrm{s}}$ & $6.25 / 0.5 \pm 0$ & 0.25 & Sy \\
\hline & $\mathrm{RS}^{\mathrm{R}}$ & $25 / 2 \pm 0$ & 1 & $\mathrm{~N}$ \\
\hline & $\mathrm{HE}^{\mathrm{R}}$ & $6.25 / 0.5 \pm 0$ & 0.25 & Sy \\
\hline \multirow[t]{3}{*}{ UA/INH } & $\mathrm{H} 37 \mathrm{Rv}^{\mathrm{s}}$ & $6.25 / 0.025 \pm 0$ & 0.25 & Sy \\
\hline & $\mathrm{RS}^{\mathrm{R}}$ & $6.25 / 0.025 \pm 0$ & 0.25 & Sy \\
\hline & $H E^{\mathrm{R}}$ & $25 / 0.1 \pm 0$ & 1 & $\mathrm{~N}$ \\
\hline \multirow[t]{2}{*}{ UA/RMP } & $\mathrm{H} 37 \mathrm{Rv}^{\mathrm{s}}$ & $6.25 / 5 \pm 0$ & 0.25 & Sy \\
\hline & $\mathrm{HE}^{\mathrm{R}}$ & $12.5 / 10 \pm 0$ & 0.5 & Sy \\
\hline \multirow[t]{3}{*}{ UA/EMB } & $\mathrm{H} 37 \mathrm{Rv}^{\mathrm{s}}$ & $12.5 / 0.5 \pm 0$ & 0.5 & Sy \\
\hline & $\mathrm{RS}^{\mathrm{R}}$ & $6.25 / 0.25 \pm 0$ & 0.25 & Sy \\
\hline & $\mathrm{HE}^{\mathrm{R}}$ & $25 / 1 \pm 0$ & 1 & $\mathrm{~N}$ \\
\hline UA/STR/ & $\mathrm{H} 37 \mathrm{Rv}^{\mathrm{s}}$ & $6.25 / 0.5 / 0.025 / 5 / 0.25 \pm 0$ & 0.25 & Sy \\
\hline INH/ & $\mathrm{RS}^{\mathrm{R}}$ & $6.25 / 0.5 / 0.025 / 5 / 0.25 \pm 0$ & 0.25 & Sy \\
\hline RMP/EMB & $\mathrm{HE}^{\mathrm{R}}$ & $6.25 / 0.5 / 0.025 / 5 / 0.25 \pm 0$ & 0.25 & Sy \\
\hline
\end{tabular}

SD: Standard deviation; in vitro MIC values are the means \pm Standard deviation, $n=3$; S: Sensitive, R: Resistant, RS: Rifampicin-streptomycin, HE: Isoniazid-ethambutol,

N: No interaction, Sy: Synergistic, STR: Streptomycin, EMB: Ethambutol, INH: Isoniazid, RMP: Rifampicin, UA: Ursolic acid, MIC: Minimum inhibitory concentration 


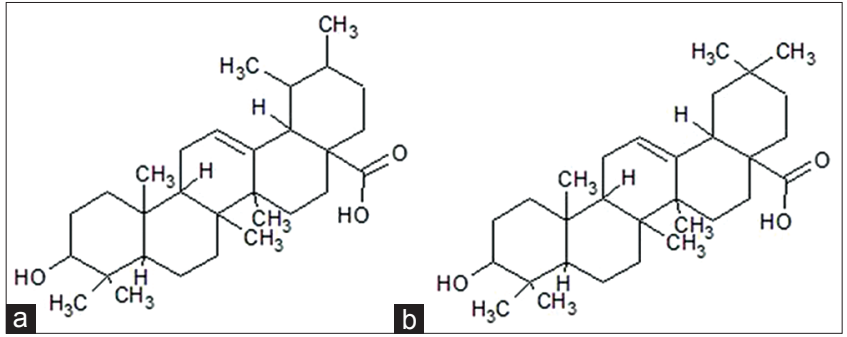

Fig. 1: Chemical structure of (a) ursolic acid and (b) oleanolic acid

Rf values which make it difficult to separate in medicinal plants. In addition, UA and OA also have similar chemical structure that makes them have similar characteristic in pharmacology properties $[16,17]$.

Many studies reported that UA and OA can inhibit the growth and survival of many bacteria, including pathogen one. Study literature data reported that $\mathrm{OA}$, other pentacyclic triterpenes, has a synergistic effect when it combined with INH, RMP, or EMB [18]. Another study showed that $\mathrm{UA}$ and $\mathrm{OA}$ found to have synergistic activity. Intracellular activity of these two compounds can inhibit the growth of mycobacteria at low doses [16].

The synergistic effects from UA and anti-TB drugs indicated that the antimycobacterial combinations were more effective than the activity of the individual agents. The decrease of MIC value resulting from the combinations indicated the improved bactericidal potentials of UA and the anti-TB drugs as combined antimycobacterial agents. The high lipophilicity of pentacyclic triterpenes is probably the main factor that allows their penetration through the mycobacterial cell wall $[18,19]$. Acids from UA affected cell morphology and enhanced autolysis of the bacterial cells. UA also can inhibit peptidoglycan turnover and affected the profile of muropeptides after digestion of peptidoglycan with mutanolysin [20]. Another study showed that the mechanism of antimicrobial action of UA has been investigated and found to be based on the inhibition of DNA polymerase [21]. In addition, triterpenes UA was found relatively non-toxic [13].

\section{CONCLUSION}

From this study, we can see that combination of UA and first-line antiTB drugs showed significant potential for the development of new antimycobacterial agent and reduction of drug resistance. Reducing the dose of STR, INH, RMP, and EMB as the result of combining them with UA hopefully can reduce the side effect caused by these anti-TB drugs. These results are preliminary but are of sufficient interest to warrant further study and indicate that UA is worthy of further investigation as a template for the development of novel antimycobacterial compounds. More study are needed on molecular basis of the synergistic interaction to understand the synergistic mechanism. For further study, we will evaluate the mechanism of action in docking molecular and in vivo testing of drug efficacy using genetic tools against MTB.

\section{REFERENCES}

1. Ducati RG, Ruffino-Netto A, Basso LA, Santos DS. The resumption of consumption -- a review on tuberculosis. Mem Inst Oswaldo Cruz
2006;101(7):697-714.

2. World Health Organization. Tuberculosis. 2014, August. Available from: http://www.who.int/tb/en/. [Last cited on $2016 \mathrm{Aug}$ ].

3. Codruta S, Camelia O, Florin B, Corina D, Cristina T, Dorina C, et al. The synergistic biologic activity of oleanolic and ursolic acids in complex with hydroxypropyl- $\gamma$-cyclodextrin. Molecules 2014;19:4924-40.

4. Gayatri R, Kalpana DP, Gunassekaran GR, Dhanapal S. Protective role of ursolic acid in den induced oxidative stress mediated hepatocellular carcinoma - A focus on thiol status. Int J Pharm Pharm Sci 2010;2(4):140-6.

5. López-García S, Castañeda-Sanchez JI, Jiménez-Arellanes A, Domínguez-López L, Castro-Mussot ME, et al. Macrophage activation by ursolic and oleanolic acids during Mycobacterial infection. Molecules 2015;20(5):14348-64.

6. Daiane M, Lillian LC, Daniela FR, Kahlil SS, Pedro EA, Barison A, et al. Anti-tuberculosis activity of oleanolic and ursolic acid isolated from the dichloromethane extract of leaves from Duroia macrophylla. BMC 2013:8:1-2.

7. De Logu A, Onnis V, Saddi B, Congiu C, Schivo ML, Cocco MT. Activity of a new class of isonicotinoylhydrazones used alone and in combination with isoniazid, rifampicin, ethambutol, para-aminosalicylic acid and clofazimine against Mycobacterium tuberculosis. J Antimicrob Chem 2000;49(2):275-82.

8. World Health Organization. Fixed-Dose Combination Tablets for the Treatment of Tuberculosis. Report of an Informal Meeting in Geneva; 1999.

9. Drake JW. The distribution of rates of spontaneous mutation overviruses, prokaryotes, and eukaryotes. Ann N Y Acad Sci 1999;870;100-7.

10. East African, British Medical Research Councils. Controlled trial offive short course regimens of chemotherapy regimens for pulmonary tuberculosis. Am Rev Respir Dis 1981;123:165-70.

11. Takayama K, Kilburn JO. Inhibition of synthesis of arabinogalactan by ethambutol in Mycobacterium smegmatis. Antimicrob Agents Chemother 1989;33(9):1493-9.

12. Telenti A, Imboden P, Marchesi F, Lowrie D, Cole S, Colston MJ, et al. Detection of rifampicin-resistance mutations in Mycobacterium tuberculosis. Lancet 1993;341(8846):647-50.

13. Liu J. Pharmacology of oleanolic acid and ursolic acid. JEthnopharmacol 1995;49(2):57-68

14. Zhang Y, Yew WW. Mechanisms of drug resistance in Mycobacterium tuberculosis. Int J Tuberc Lung Dis 2009;13(11):1320-30.

15. Wójciak-Kosior M. Separation and determination of closely related triterpenic acids by high performance thin-layer chromatography after iodine derivatization. J Pharm Biomed Anal 2007:45(2):337-40

16. Jiménez-Arellanes A, Luna-Herrera J, Cornejo-Garrido J, LópezGarcía S, Castro-Mussot ME, Meckes-Fischer M, et al. Ursolic and oleanolic acids as antimicrobial and immunomodulatory compounds for tuberculosis treatment. BMC Complement Altern Med 2013;13:258

17. Mestry D, Dighe V. Separation and determination of triterpene acids by using high performance thin layer chromatography from stem bark of Mimusops elengi Linn. Int J Pharm Pharm Sci 2014;6(1):313-7.

18. Ge F, Zeng F, Liu S, Guo N, Ye H, Song Y, et al. In vitro synergistic interactions of oleanolic acid in combination with isoniazid, rifampicin or ethambutol against Mycobacterium tuberculosis. J Med Microbiol 2010;59:567-72

19. Joseph B, Priya MR. In vitro antimicrobial activity of Psidium Guajava 1. Leaf essential oil and extracts using agar well diffusion method. Int $\mathrm{J}$ Curr Pharm Rev Res 2010;2(3):28-32.

20. Kurek A, Grudniak AM, Szwed Ma, Klicksa A, Samluk L, Wolska K, et al. Oleanolic acid and ursolic acid affect peptidoglycan metabolism in Listeria monocytogenes. Antonie Van Leuwenhoek 2010;97:61-8.

21. Deng JZ, Starck SR, Hecht SM. Pentacyclic triterpenoids from Freziera sp. that inhibit DNA polymerase beta. Bioorg Med Chem 2000;8(1):247-50 